\title{
Risk Factors Associated with Domestic Violence and Homicidal Violence of Women: The Case of Yucatan, Mexico
}

\author{
Yolanda Oliva Peña, Andrés Santana Carvajal, Guadalupe Andueza Pech, \\ Jolly Hoil Santos, Ricardo Ojeda Rodríguez, Gerardo García Gil, \\ Elsa María Rodríguez Angulo, Manuel Ordóñez Luna \\ Regional Research Center "Dr. Hideyo Noguchi”, Yucatan Autonomous University of Mexico, Merida, Mexico \\ Email:opena@correo.uady.mx
}

Received 26 November 2015; accepted 17 January 2016; published 20 January 2016

Copyright (C) 2016 by authors and Scientific Research Publishing Inc. This work is licensed under the Creative Commons Attribution International License (CC BY). http://creativecommons.org/licenses/by/4.0/

c) (†) Open Access

\begin{abstract}
The manuscript presents results of research conducted with the aim of analyzing the association of geographic areas and risk factors of violence to women occurred in the state of Yucatan during 1997-2014, by reviewing statistics and other sources. Variables domestic violence, sex crimes and homicides and femicides association and risk according to the degree of marginalization, town size and percentage of population analyzed Maya. The main findings of the research show the presence of violence in 49 of the 106 municipalities. Association found the urban condition in cases of domestic violence, sexual offenses, homicide, and femicide, while for domestic violence it was obtained that the condition of Maya speakers is a risk factor. The geospatial distribution shows areas of high violence mostly in the south and east of the state. Some municipalities' rates for homicide and domestic violence, are higher compared to the national and state average rates recorded. It is concluded that information management has been the key to catalog the state as low gender violence and that the results presented here show the presence of large geographical areas of high risk for the lives of women, which requires your attention of inter-sectoral public policy.
\end{abstract}

\section{Keywords}

Domestic Violence, Killings of Women, Femicide, Sexual Crimes

\section{Introduction}

Mexico has gone through changes in living conditions since 2009, with significant growth of cases of homicidal

How to cite this paper: Peña, Y. O., Carvajal, A. S., Pech, G. A., Santos, J. H., Rodríguez, R. O., Gil, G. G., Angulo, E. M. R., \& Luna, M. O. (2016). Risk Factors Associated with Domestic Violence and Homicidal Violence of Women: The Case of Yucatan, Mexico. Psychology, 7, 62-73. http://dx.doi.org/10.4236/psych.2016.71008 
violence, and other more complex, crisis social, economic and personal expressions that impact the security to guarantee the life. The homicide rate per 100,000 population in 2000 was 7.2 while for 2010 it was 16.5. In 2015 they occurred at least 2 murders per hour, about 49 a day for the first half of this year. If this trend continues, by 2015 more than 16,000 total violent deaths are estimated (Aristegui, 2015).

Some factors such as migration, unemployment, poverty and the increasingly widespread presence of drug trafficking in our environment have expressed the complex nature of violent deaths; diverse indicators' socioeconomic, geospatial, and cultural vulnerability are multiple faces of gender violence; complexity requires a multidimensional view of the problem.

The different levels of gender violence like the extreme expression, and homicidal violence are a matter of political and public character (Soberón, Zurita, Ramírez, \& Torres, 2000). Identifying characteristics, magnitude and intensity of the problem of violence against women is not easy, mainly because of lack of political commitment and dialogue interinstitutional to generate information systems that make the deaths and domestic violence evident; documented difficulties, scarce resources and skills in the management of statistical information of the institutions are related to the topic (Ortega-Canto, Munguia-Gil, Oliva-Peña, \& Rodriguez-Sosa, 2009).

In this research we start from the understanding of gender-based violence as a social construction, which now needs to be analyzed and understood from different perspectives given the influence that social, historical and ideological context exerted on it. Precisely the family is one of the contexts in which violence occurs at an alarming rate, (Domenech et al., 2002). According to reports from this author, all combinations are possible and the media are responsible for providing evidence of it; parents against children, partners against each other, brothers against brothers, and children against parents; so it looks like a modern phenomenon when in fact it is as old as the family itself problem. From the look of this author, family violence should not only be understood as a recent social problem, but it requires the analysis of a number of socio-historical factors that family violence can be explained and seen also as a social and political. In its conclusions it suggests that the discourses of violence are related to specific times and methods and companies that generate different values to define confrontations, situations, interactions and causes. They are always intertwined with other dimensions such as race, ethnicity or gender, forming a whole of the defining features of a culture that can be highly or moderately violence against women and other groups unprotected.

Today, in a globalized world where many ways of being human coexist, the multiplicity of possible interactions is very diverse; hence contemporary societies are characterized by a large and complex heterogeneity; Carvallo (2006) suggested that one of the greatest ethical, scientific and democratic challenges to the process of inclusion and exclusion in theory, research and intervention in interpersonal relationships, was faced. All this leads to the analysis about the social transformation of the various institutions and at the same time the fact that many organizations seek to achieve through its various institutions, law or science itself, values such as freedom, justice and equality and the right to a safe and dignified life.

Coinciding with the vision of Robles and Cazares (2009), the reflections developed in this paper are guided not so much on the ideal of equality and equity between men and women according to which the common good of both is sought unprotected sex without leaving any of them; condition which is necessary in science. In this regard and as noted Robles \& Hurtado de Mendoza (2009), the goal would be for humans to better educate new human beings to stop fighting for equality and the right to a life free of violence and focus more on inequalities differences to learn to live and live with them in a better way than has been done so far and to facilitate more equitable between men and women to preserve the life and dignity of those relationships.

The identification of violence in couples as a public health has been a social, political and ideological progress; yet their characteristics have meant a real conceptual and methodological challenge because depending on the theoretical or ideological approach taken for explanation, individual prevail, structural and cultural factors, although research on issues of violence has increased in recent years, not so with the conceptual and methodological consensus, so it seems that many investigations, but little scientific theory to support them. However, for feminist or based on "Theory of Gender" studies there is little doubt, contemplating violence against women as the result of a patriarchal society where the male has the dominant role and has exercised power (Reed, Raj, Miller, \& Silverman, 2010). According to Alencar-Rodrigues \& Quarry (2012) there is a consensus among several theorists (as) to suggest that violence in relationships is a universal problem present in all cultures, social classes, ethnic groups, religions and ages, and is a violation human rights. For her, the concept of violence of the approach set out by the United Nations Conference in Beijing in 1995 which provides that "violence against women means any act based on gender which results in psychological harm, sexual, physical including 
threats of such acts, deprivation of liberty" and therefore the concept of gender, enrolled in the term gender violence, it refers to the beliefs, attitudes, feelings, values and behaviors that make the difference between men and women through a process of social construction.

Alencar-Rodrigues \& Quarry (2012) notes that among the different theories that explain the phenomenon of violence in the relationship for a better understanding, are the biological, social, cultural, psychological and ecological line; and the latter, coupled with the gender make up the paradigm from which it partly to understand and explain this phenomenon. She argues that the focus of the gender perspective prioritizes the patriarchal model to explain the abuse that prevails in society against women; it sustains studies by Walker (2004) and Fernandez (2006), who warn that the gender perspective is concerned with analyzing cultural and social issues, conceiving male violence against women as an abuse of power in a social structure that favors agreed men and women that favors male over female elements.

Also, Cantera (2004) understanding of violence against women is facilitated when this phenomenon is in the context of patriarchal culture. For her patriarchy is a way of sociocultural organization in which male dominance structure social relations based on asymmetric relationships and hierarchical power. In this scenario, the division of male and female roles is set, and the actors which attributed the role and duty to exercise violence and characters that are subject to receive defined. Therefore, patriarchy sees women as the object of control and domination by a male and oppressive social system.

Thus, various international organizations such as the World Health Organization (WHO, 2003) recommend using the ecological model to explain the gender violence in the couple to identify protective factors against this problem. Since 1987, Heise explains that this theoretical perspective was proposed to organize the results of studies on child abuse and subsequently used for the issue of abuse in the couple (Heise, 1987). Thus this author suggests the adoption of the ecological structure as a useful tool to compile a lot of existing research and understand gender violence in couples in an inclusive manner.

Bronfenbrenner $(1977,1987)$, who is the hammer of this ecological approach, states that the understanding of human development requires going beyond the observation of behavior and involves examining the interaction systems and the characteristics of the environment where the behavior occurs. Following the approach of Bronfenbrenner (1987) states that are various causes that give rise to gender-based violence in the couple and recommends a look that considers the interaction of cultural, social and psychological factors.

This ecological approach, according to Roberta de Alencar (2012) provides an integrated reading of gender violence in couples, to understand this phenomenon from the interplay of interpersonal, individual and sociocultural levels, as it is distinguished from other models theorists who consider only part of the problem. It is also a useful model for thinking and explain gender violence in the couple immigrant women, allowing to understand the factors that shaped the emergence of this phenomenon are different. Therefore, as Turinetto and Vicente (2008) also points out, gender is a structure that organizes social, family and individual.

Therefore, and there has been difficulty from history, to understand and recognize violence against women. Two basic processes mentioned Corsi (2002) are the invisible and naturalization. The invisibility of male partner violence is directly linked to the lack of conceptual tools to identify it as an object of study. One of the biggest epistemological barriers that this author has found is the notion of "family", understood as the private space par excellence, as abstract and sacred concept. From the modern and religious vision of the family, it was defined as an idealized place, like a nurturing context, a provider of security, affection, containment, boundaries and stimuli. This skewed view of family life in years delayed the ability to visualize the other side of the family as a potentially dangerous environment in which can also be violations of human rights, in which you can experience fear and insecurity and the all variations of violent interpersonal conflict resolution are learned.

The other process, the naturalization of violence often results in popular expressions that reflect the legitimating cultural pattern ("the rod and spoil the child", "a good beating in time hassle", "women are to be taken little" "Here we need a strong hand", etc.). Thus, victims often become trapped in the midst of a social "consensus" that prevents them aware of their rights and how they are being violated (Jorge Corsi). Corsi (2002) refers to gender violence as the whole way in which you try to perpetuate the system of hierarchies imposed by the patriarchal culture; It takes many forms, both in the public sphere and in private contexts, for example, forms of discrimination against women in various levels (political, institutional, labor), sexual harassment, rape, trafficking women for prostitution, the female body as an object of consumption, segregation based on religious ideas and, of course, all forms of abuse physical, psychological, social, sexual suffering in any context, and which cause damage scale that can culminate in death (2002). 
In this regard, Lagarde (2011) is a review of the violence against women and that this phenomenon has transcended the borders of Mexico because the organizations supporting families of the victims have turned to international bodies for pronouncement and denunciation. The author analyzes the crimes of girls and women in Ciudad Juarez and the label as femicide based on feminist theories of Diana Russell and Jill Radford. Thus, for Lagarde (2011) femicide is the set of violations of human rights of women containing crimes and disappearances of women and that they were identified these as crimes against humanity. Femicide is genocide against women and happens when the historical conditions generate social practices that allow violent acts against the integrity, health, freedoms and lives of girls and women.

Lagarde (2011) indicates that femicide is forged in the structural inequality between women and men, as well as the domination of men over women, who are in domestic violence, a playback mechanism of oppression of women. Of those structural conditions arise as other cultural conditions are the ideological and social environment of machismo and misogyny, and normalization of violence against women. Also, legal and democratic political absences add up gender content of government and organs of state courts, resulting impunity generates more injustice and unsafe living conditions, threatening his life and promotes the set of violence against girls and women. Femicide contribute to the social silence, neglect, the idea that there are more urgent problems and shame and anger come on not transform things but to diminish the fact and show that they are not so many "dead" or not here as in Juarez, India or Guatemala, or also states, it is not femicide, only crimes against women and girls occurs.

The Global Study on Homicide 2013 seeks to shed light on the worst of crimes, the intentional killing of one human being by another. The international homicide caused the deaths of almost half a million people $(437,000)$ across the world in 2012. The 36 per cent occurred in the Americas. 31 per cent in Africa and 28 per cent in Asia, while Europe (5 per cent) and Oceania (0.3 per cent). The number of women killed intimate bay partners and family members on Africa in 2013 was 13,400, 6900 Americas, Asia 19,700, 3300 and Ocean Europe 200.

Echeburúa and De Corral (2009) notes that in Spain between 50 and 75 women die annually as a result of intimate partner violence, which represents a rate of 3.1 women killed per million inhabitants. The victims are between 30 and 45 years, of low and medium low socioeconomic status. Find that marginalization, migration and addictions increase the risk murder. It says that more than a third are separated and the authors recorded that there is an increased number of killings carried out by the former partner.

Subregion analysis shows that Central America is one of the most violent regions in Latin America with 29.3 homicides per 100,000; South America and the Caribbean 25.9, 18.1\% (UNODC, 2013). According to the Observatory of gender equality in Latin America of the Economic Commission for Latin America (CEPAL, 2014) shows that 17 countries have records of femicide, in 2014 were registered 1678 dead women with an average distribution of 98 femicides and the country with the lowest number of cases Dominican Republic as the country with the largest number of cases was Honduras with 531, followed by Guatemala with 217.

Moreover, in the national context, the National Institute of Statistics, Geography and Information (INEGI, 2011) reported that the results of the National Survey on the Dynamics of Household Relationships, in relation to gender violence, 63 of 100 women aged 15 and over reported having experienced an incident of violence, either by your partner or any other person or persons. Women more unprotected to violence of any aggressor are women between 30 and 39; $68 \%$ of them have faced at least one episode of violence or abuse. Chihuahua reaches $80 \%$ and the state of Mexico 78 percent. 47 of every 100 women aged 15 years and over who have had at least one relationship, marriage or dating, have been assaulted by a current or last couple throughout their relationship.

According to the type of violence, emotional is the one with the highest prevalence (44.3\%), and occurs primarily by the partner or spouse (43.1\%). By contrast, sexual violence has been experienced by just over a third of all women (35.4\%), but particularly exercised by different aggressors the couple and their different forms, from intimidation, abuse or sexual hassment. Although the level of this type of violence where the aggressor is the couple's minor acts of sexual violence are more severe. Physical violence is largely confined to attacks by the couple. In terms of economic violence, it includes control and financial abuse by an intimate partner, dispossession by other aggressors, discrimination at work occurred in the last year and various discriminatory ways.

Between 1985 and 2010 the cumulative murders of women in Mexico was 36.606. In 2010 they occurred an average of 6.4 homicides of women every day. The homicide rate for women in 2010 represents 106.2 percent compared to 2007. 
Studies in Mexico suggest that homicidal violence, is multifactorial (Delgado Rodriguez-Rivera \& Gonzalez Pulido, 1993; Gonzalez-Perez et al., 2012) and in particular femicide is not possible to reduce or eradicate with the creation of laws (Echeburúa \& De Corral, 2009), because among other factors are the degree of citizen security, political and socio-economic conditions such as marginalization type of employment, drug use among others (Briceño-León, 2008; Ybáñez, 2013; Yanes, 2006).

Gomez (2002) found that female homicides realize that women have rights condition undercutting which has helped to keep gender discrimination, domestic violence and sexual offenses as structural facts.

Monárrez and Fuentes (2004) conducted a study on femicide and urban marginality in the nineties, mention that the urban structure involves vulnerability to a particular group of women in Ciudad Juarez under study; femicide in this city, is directly related to social vulnerability condition. Since the murdered women is higher when living in underserved areas of urban infrastructure and carry out work in maquiladoras that have to travel from one end to another city and another substantial number because of their employment status of prostitutes, dancers or employees of bars.

Olaiz, Rojas, Valdez et al. (2006) in a study of the prevalence of different types of violence are health sector in Mexico found that $7.8 \%$ of women answered affirmatively to the general question of partner violence. However, applying the scale of violence, the prevalence of any type of violence in the last 12 months was $21.5 \%$. The most common form of violence was psychological (19.6\%). Of the women who had been pregnant, $14.1 \%$ reported violence and $4.4 \%$ reported being hit in the abdomen. The prevalence of sexual violence was $17.3 \%$ and about half of this percentage suffered before the age of 15 . Violence occurs in more prevalent among less educated, who do not live in their own home and live in overcrowded.

Gonzalez-Perez et al. (2012) study analyzing the trend in homicide rates (total and firearm) in Mexico between 1990 and 2009 and identifies the variables that best explain the geographic variations in rates in 20082009. Finds that the homicide rate declined between 1992 and 2007, but has doubled in the last two years (from 7.6 to 16.6 per 100,000). The geographic analysis in this study shows that the rate of male and female homicides are virtually the same states that have the highest and the lowest rates; Among women, the distance between the ends is slightly smaller than in the case of men, a woman of Chihuahua - located state where the infamous Juarez-has almost 23 times more likely to be murdered than a Yucatan.

The road begins to document the female homicides from the legal field in Mexico in 2003 when Marcela Lagarde is invited to become deputy. A diagnosis of femicide was performed; it was investigated from official information about what happened between 1999 and 2006, only about intentional and wrongful death. They wanted to know the extent of the problem both in Ciudad Juarez and the rest of the country. Crimes against girls and women were placed in the context of domestic violence and in relation to all forms of violence against girls and women who are on official information. Also, the Law on Access of Women to a Life Free of Violence of the State of Yucatan, promulgated on March 20, 2008 (the regulations dated 11 June the same year), and the State Penal Code was passed.

Meanwhile the Special Commission to monitor femicide of the Chamber of Deputies of reporting on Yucatan in reporting the occurrence of female deaths in the municipalities: in 2005 there were two in Merida, one in Ticul and the other in Chacsinkín and in 2009 one in Mérida and two Tizimín. Also, only 0.2\% loss in the Gender Development Index (GDI) is attribute to partner violence against women.

According to National Survey, (INEGI, 2006) in Yucatan percentage of single women aged 15 and older who reported incidents of communal violence throughout his life it is 39.3\%. Moreover, among women 15 and older married or cohabiting, $35 \%$ were incidents of intimate partner violence in the last year, with what the state ranks $23^{\text {rd }}$ in the country, $6.8 \%$ reported incidents of emotional partner violence in the last year, $8.7 \%$ physical violence and 5.6\% couples incidents of sexual intimate partner violence (twentieth place). In this same group of women, those who suffered episodes of physical or sexual violence by an intimate partner over their current or past relationship, 23.5\% had a complaint ratio 32\% higher than the national average which places Yucatan fourth. Some studies found Yucatan municipalities on domestic violence, Oliva-Peña \& Santana-Carvajal (2004) in a sample of 208 women $34.1 \%$ of women reported emotional violence, $20.2 \%$ physical violence a private $18 \%$ of freedom, and $14 \%$ sexual violence. Rodriguez-Angulo, Andueza-Pech, \& Montero-Cervantes (2012) with the families of 14 women died due to maternal complications, show that women who suffered violence by the husband says. They have mentioned that the abandonment without food or a decent home. They also expressed that they hit and cause abortions and they do not say anything for fear of being beaten again. Also in a pilot study with 238 women in 2007, the prevalence of violence against women and children in the town of Chicxulub 
Puerto was studied. The results showed prevalence of family violence in $49 \%$, physical violence against women in couples $16.8 \%$ in a single episode of moderate intensity; emotional violence against women $44.5 \%$, for several episodes of moderate intensity; physical to the minor $27 \%$ and for several episodes violence (unpublished data).

Another study by the research, case-control study in 2007, 270 cases of women with major depressive disorder and 540 without the disorder were studied. They presented emotional violence $32.2 \%$ of cases and $14.4 \%$ of controls. The presence of violence in the overall family environment or otherwise significantly associated with the presence of depressive disorder $\left(X^{2}=61,948, \mathrm{df}=1, p=000\right)$ (unpublished data).

One in 100 pregnant women Tahdziu, violence between the years 2006-2011 studied and found an overall prevalence of $29 \%$ : $24 \%$ psychological violence, $12 \%$ physical violence and $12 \%$ sexual violence. Violence associated with products low birth weight (OR 2.86, CI 1.39 - 5.93) (unpublished data).

So far there are few studies in the entity associated risk factors for femicide and other gender violence, with the analysis of geospatial distribution at the same time, the data is not recent; the methodology used in these studies, Yucatán ranks as a low-status women murderer. The proposed analysis and the results shown by this work, let have indicators of risk of femicide gender violence; and contribute to the transfer of technology to establish a surveillance system for the prevention and eradication of gender violence and particularly prevent femicide. In this paper we answer the question "What risk factors are significantly associated with gender violence in the state?”

\section{Material and Methods}

Documentary research, analytical, retrospective, comparative studying geo-spatial indicators of gender violence with direct and indirect sources. The overall objective is to analyze the association of four indicators of gender violence in order to identify geographic areas at risk of domestic violence.

Inspired by the ecological model of violence, the variables were selected to address different areas. For the family/staff/relational: domestic violence, the social: the killings of women and cultural: feminicidos and sexual offenses. Also, vulnerabilities of different nature were incorporated socio-economic (level of poverty); Geospatial (locality size and geographic distribution) and cultural (percentage of population Maya).

\section{Procedure}

Historical statistics were revised four variables namely: domestic violence, killings of women, Femicide and sexual offenses. Data were collected from surveys and databases INEGI; As databases attorney general of the state of Yucatan and records of the Ministry of Health of the state of Yucatan, as well as research results feminist NGOs Women Network (2010). The information covers 1997 to 2014. In addition, data from the National Population Council (CONAPO) for the index of marginalization by municipality were consulted. The data of domestic violence cases are registered by the secretary of health in the various modules of attention of the state.

\section{Results}

$51.86 \%$ of the chaos of domestic violence occurred in housing, $7.78 \%$ in school or sport; on public roads, public transport, accommodation, canteen etc. was $29.4 \%$ in the rest others. The means to cause gun violence were 2.05\%, 18.87 Vehicle; hitting, pushing, 28.5\%; 3.2 Hanging, inhalation of substances, among others; 8.77\% with animal bite, the rest others. The report on the perpetrators realize that in $50.24 \%$ refers to the spouse, the $22.15 \%$ known unrelated to the $11.20 \%$ to $15.5 \%$ relatives and strangers, that adding the set of people close to the family as personally sheds or $83.6 \%$, which reveals the proximity while events are preventable. The ages of the victims show predominance in young women between 20 and 29 years with $31 \%$ of registered cases and $40 \%$ to $49 \%$ to $29 \%$.

The distribution of cases of domestic violence by locality size shows a greater presence in localities of less than 5000 inhabitants and secondly towns of over 15,000 inhabitants, which suggests a multiple behavior, which is not exclusively urban, significant association this factor. Because it relates to the distribution of cases of killings of women a slight preponderance in urban municipalities is appreciated, while the established femicide show a clear urban bias, as well as cases of sexual crimes, with $80 \%$ and $91.66 \%$ respectively. Murders of women by associating with the size of town a value of chi-square 0.005 with a value of $p<0.005$ and an odds 
ratio of 2.1 indicates that constitutes a risk factor was obtained. The distribution of cases of sexual offenses by size of locality of occurrence is shown and a strong influence can be seen in the towns of over 15,000 inhabitants, reaffirms its urban character. The association of variables with chi square 0.000 a value of $p<0.005$ and an odds ratio value of 2.045 indicating risk factor. The distribution of femicide typified by size of locality shows a predominance in urban areas of over 15,000 inhabitants, i.e. exhibits behavior of urban cases. By associating Feminicides typifed size town with a chi-square value of 0.001 with a value of $p<0.005$ and an odds ratio of 10.1 relates risk value was obtained (Table 1 ).

Then geospatial distribution of recorded cases of violence accumulated 2010-2013 showing predominance of the south, the east and the city of Merida, a city of high percentage of cases and that is the indicator has studied comprising 45 municipalities (Figure 1).

\section{Killings of Woman}

The murders of women in the State observed an upturn from the year 2011 to find a similar to that recorded in 2007 (Table 2). The age distribution of deaths in 2013 shows that $40 \%$ were between 25 and 34 years. Also $33.33 \%$ of them occurred because of domestic violence, $80 \%$ in this age range. Standardized femicide show 33\% occurred in women between 15 and 24 years and a 12\% increase between 30 and 34, allowing point that occurs in relationships from dating to married life and are preventable femicides. The distribution rates in municipalities with record of killings of women in 2013, see table allowing most high rates, higher than the national and local tax comes, highlights the municipality Tinum with a rate of 16.50, representing 3.79 times higher.

The geographical distribution shows that homicides of women are present in very high levels in the east and the principal center of the state, and secondly south of the state (Figure 2).

The rate of sexual offenses observed a pattern of municipalities with the highest rates, with an upturn in 2010 in Merida, followed by Tekax, Tizimín Izamal and Valladolid, with a systematic behavior fundamentally important cities in the state, then presented the data from the five municipalities with the highest rates register in each year (Table 3).

The analysis of the risk factor level of poverty shows the following results (Table 4). The distribution of cases of violence by level of poverty shows an almost equivalent distribution in the different degrees of marginalization, leading to assume an extended presence. By associating cases of domestic violence with a value marginalization chi square $0.008 p<0.005$ and an odds ratio of 7.73 with a value greater than 1 indicates that risk is obtained. The data of murders of women by degree of marginalization show a greater number of cases in areas of middle marginalization. The value of chi-square association is $0.00195 \%$ confidence and odds ratio value of 4.36, indicating greater than one risk in this partnership. When analyzing the sexual offenses Variable submitted a trend mainly in towns of medium or low marginalization is observed, this is explained by their geographical distribution, mainly in urban areas. A strong relationship between the presence of sexual offenses to the degree of marginalization, registering the highest percentage in middle level, with a significant association chi square 0.001 with $95 \%$ confidence, showing no risk factor, the record will notice a value less than 1 . Femicide by degree of marginalization show a tendency to medium marginalization, which is in line with its eminently urban character.

The distribution by degree of marginalization municipalities of Yucatán shown in Figure 3.

The distribution of cases of violence Maya percentage of population shows an increasing trend in the number of cases in the medium to high grade with $63 \%$ of the municipalities that recorded cases of domestic violence. By associating cases of domestic violence with a value marginalization chi square $0.002 p<0.005$ and an odds

Table 1. Regarding the size of the town with the presence of cases of violence, women in killings, femicide and sexual crimes municipalities in Yucatan Mexico.

\begin{tabular}{ccccc}
\hline Risk factor & $\begin{array}{c}\text { Municipalities with cases } \\
\text { of domestic violence }\end{array}$ & $\begin{array}{c}\text { Municipalities with cases } \\
\text { of killing of woman }\end{array}$ & $\begin{array}{c}\text { Municipalities with cases } \\
\text { of femicide typified }\end{array}$ & $\begin{array}{c}\text { Municipalities with cases } \\
\text { of sexual offenses }\end{array}$ \\
\hline Locality size & & & & \\
Until 14,999 & 29 & 11 & 2 & 1 \\
Of 15,000 & $(64.44)$ & $(44)$ & $(20)$ & $(8.33)$ \\
and more & 16 & 14 & $(80)$ & 11 \\
\hline
\end{tabular}




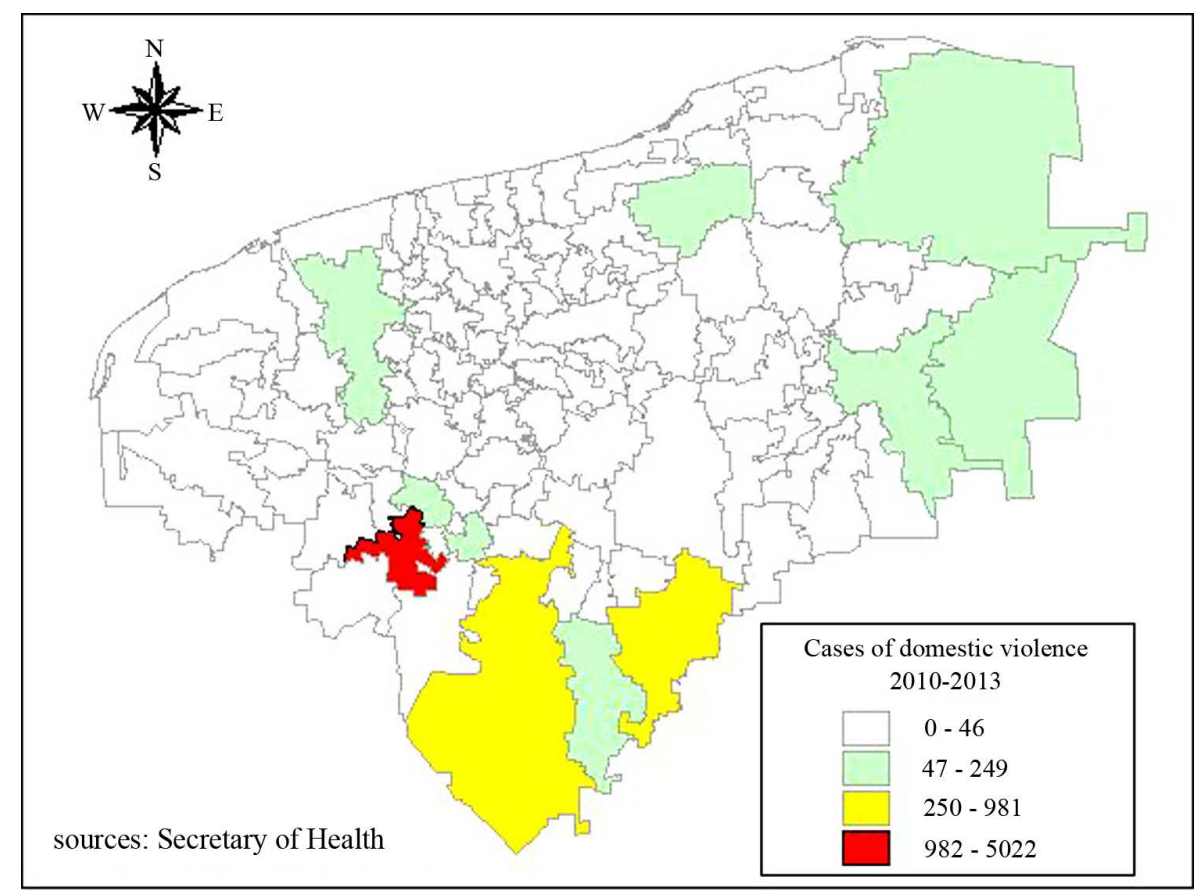

Figure 1. Distribution of domestic violence cases by municipality 2003-2013.

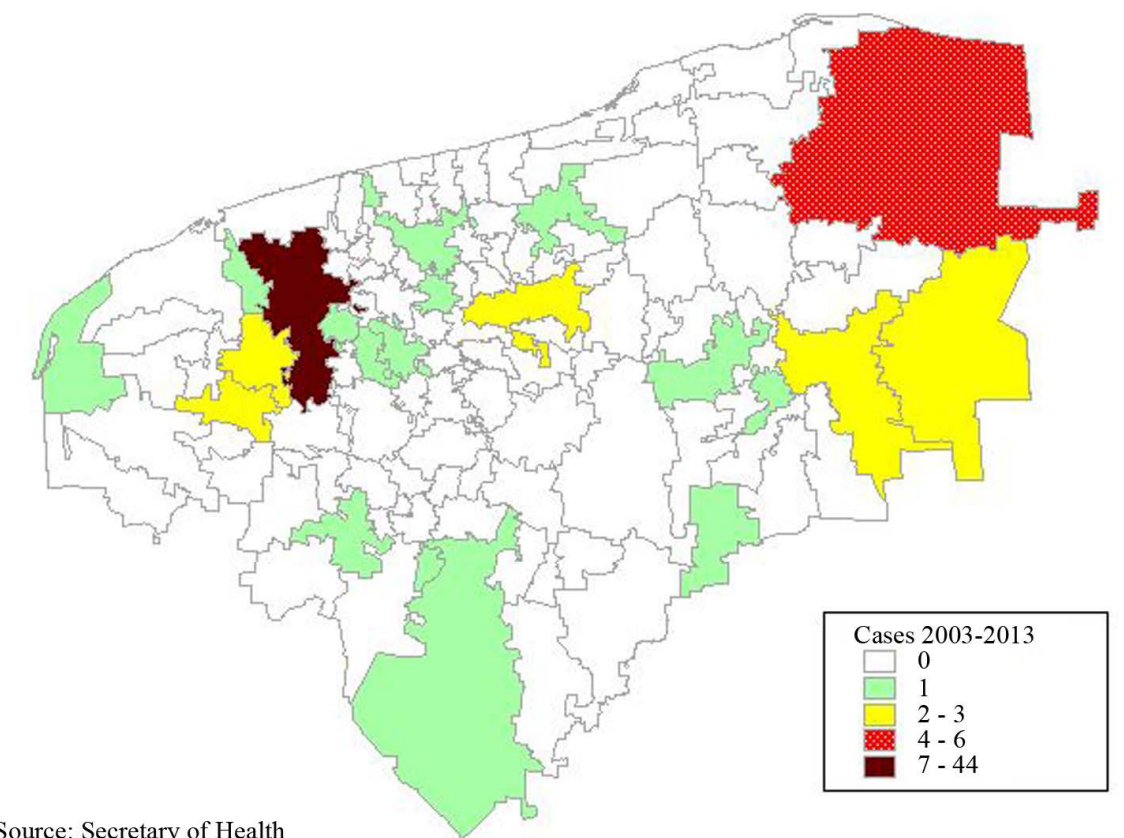

Source: Secretary of Health

Figure 2. Distribution of women’s homicides by municipality 2003-2013.

ratio of 2.5 with a value that indicates risk is obtained. Meanwhile, the distribution of homicides of women, femicide and sexual offenses shows a higher number of cases in low and very low percentage of the population Maya, in it is a phenomenon of urban nature, with percentages of $72 \%, 90 \%$ and $83 \%$ respectively; calculating chi square value indicating a significant association with a 0.003 and $p<0.005$ and an odds ratio of 6.2 to greater than one referring to murders of women risk value is obtained; 0.005 And with a value of $p<0.005$ and an odds ratio of 9.3 with more than one risk for femicide refers to sexual crimes and 003 without risk factor, with a 


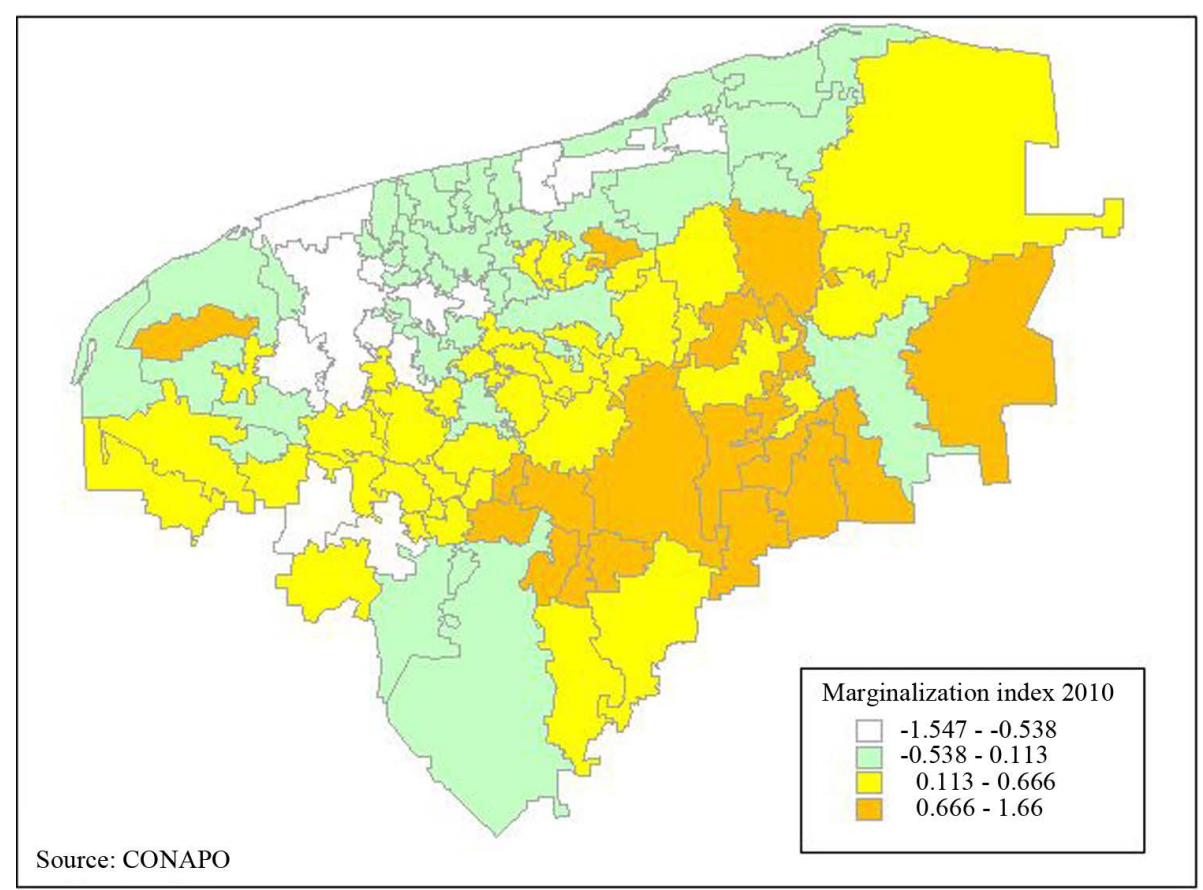

Figure 3. Index of marginalization by municipality. State of Yucatan Mexico 2010.

Table 2. Distribution rates of murders of women in the 2013.

\begin{tabular}{|c|c|}
\hline $\begin{array}{c}2013 \\
\text { Killing women }\end{array}$ & $\begin{array}{c}2013 \\
\text { Killing women }\end{array}$ \\
\hline Rate 100,000 population & $\begin{array}{l}\text { Tinum } \\
16.50\end{array}$ \\
\hline \multirow[t]{6}{*}{$\begin{array}{c}\text { Nacional } \\
4.369133228\end{array}$} & $\begin{array}{c}\text { Acanceh } \\
12.23\end{array}$ \\
\hline & $\begin{array}{c}\text { Tekax } \\
5.54\end{array}$ \\
\hline & $\begin{array}{l}\text { Motul } \\
5.53\end{array}$ \\
\hline & $\begin{array}{l}\text { Umán } \\
4.61\end{array}$ \\
\hline & $\begin{array}{l}\text { Mérida } \\
3.85\end{array}$ \\
\hline & $\begin{array}{c}\text { Yucatan } \\
1.24\end{array}$ \\
\hline
\end{tabular}

value of 0.676 value. Integrated analysis of indicators of violence studied (Table 5).

A total of 59 municipalities with indicators of violence, in 55.6\% recorded gender violence occurred; Merida, Progreso Ticul, Tizimin and Uman are municipalities that have recorded the four indicators of violence selected for this study. Domestic violence, homicidal violence, sexual offenses and femicide therefore femicide are considered high risk, along with Kanasín, Valladolid, Tekax, Motul and Izamal 3 municipalities where indicators. In turn, the municipalities of Celestun, Tinum, Cacalchen, Cenotillo, Chemax, Maxcanú, Temozón and Chaksinkin have two indicators, with a medium level of risk; finally, 41 municipalities recorded at least one indicator, in, latent risk. The distribution shows that the geographical areas correspond to the south, east and the metropolitan area, which account for systematic severity and frequency, as structural facts (Figure 4).

By associating the variable to find significance in domestic violence variable associated with sexual offenses a significant value of chi square is not obtained; meanwhile the association of domestic violence homicides of women shows a value of 0.002 with a value of $p<0.005$ and 2.52 odds radius value, value that indicates risk. 


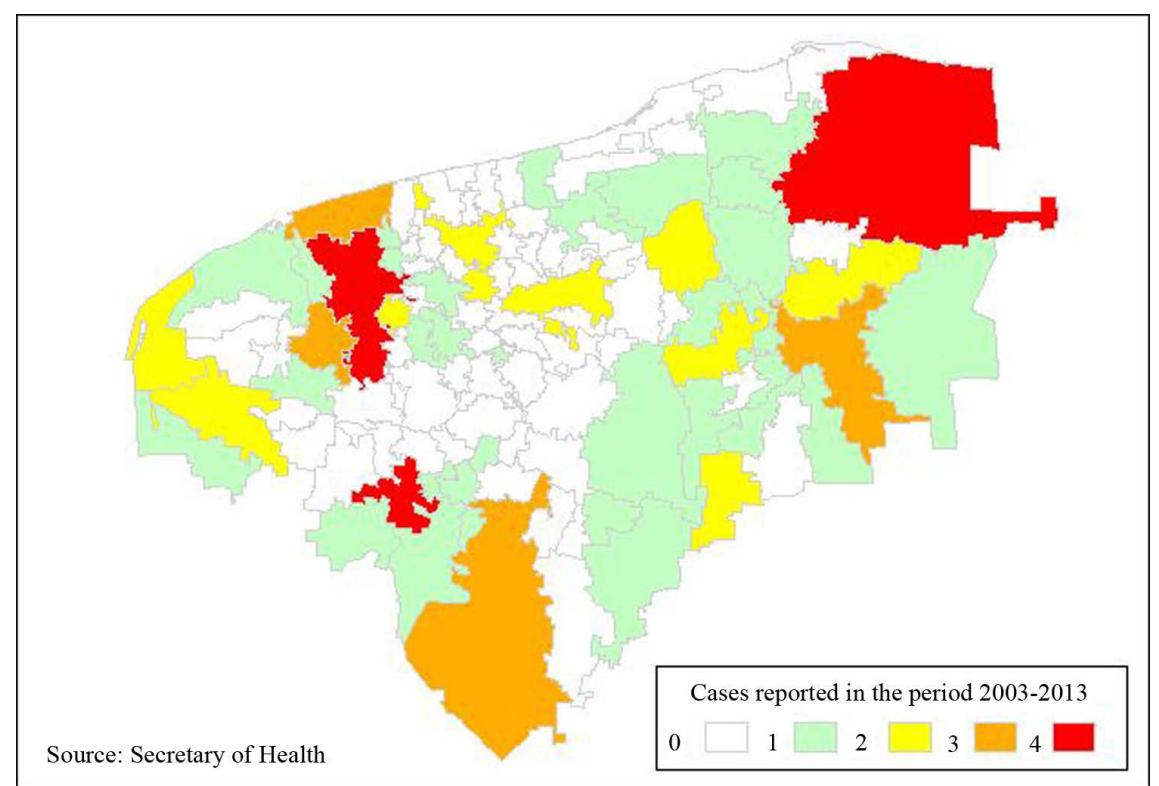

Figure 4. Distribution of incidences of violence against women by municipality.

Table 3. Distribution of rates of sexual offenses per year and municipality.

\begin{tabular}{|c|c|c|c|c|c|c|c|}
\hline 1994 & 1996 & 2004 & 2005 & 2007 & 2008 & 2009 & 2010 \\
\hline Tekax & Tekax & Tekax & Mérida & Mérida & Mérida & Mérida & Mérida \\
\hline 20.45 & 11.16 & 13.20 & 11.56 & 12.90 & 12.90 & 13.06 & 15.49 \\
\hline Mérida & Valladolid & Mérida & Tekax & Tekax & Tekax & Tekax & Tekax \\
\hline 12.18 & 6.05 & 11.78 & 7.92 & 10.56 & 8.26 & 8.26 & 11.18 \\
\hline Maxcanú & Mérida & Valladolid & Ticul & Tizimin & Ticul & Tizimin & Tizimin \\
\hline 7.68 & 4.57 & 10.62 & 7.79 & 9.19 & 6.29 & 8.18 & 7.36 \\
\hline Tizimin & Tizimin & Ticul & Valladolid & Valladolid & Tizimin & Dzizantún & Izamal \\
\hline 7.23 & 4.27 & 6.68 & 7.46 & 6.60 & 4.91 & 4.98 & 4.58 \\
\hline Valladolid & Izamal & Tizimin & Tizimin & Progreso & Valladolid & Ticul & Valladolid \\
\hline 7.18 & 3.36 & 6.03 & 5.46 & 4.44 & 4.26 & 4.71 & 4.26 \\
\hline
\end{tabular}

Table 4. Relationship with degree of marginalization occurrence of violence, homicide and women, femicide and sexual crimes municipalities in Yucatan Mexico.

\begin{tabular}{|c|c|c|c|c|c|c|c|c|}
\hline \multirow{2}{*}{\begin{tabular}{|l} 
Risk factor \\
Marginality
\end{tabular}} & \multicolumn{2}{|c|}{$\begin{array}{c}\text { Municipalities with cases } \\
\text { of domestic violence }\end{array}$} & \multicolumn{2}{|c|}{$\begin{array}{l}\text { Municipalities with cases } \\
\text { of killing of woman }\end{array}$} & \multicolumn{2}{|c|}{$\begin{array}{c}\text { Municipalities with cases } \\
\text { of femicide typified }\end{array}$} & \multicolumn{2}{|c|}{$\begin{array}{l}\text { Municipalities with cases } \\
\text { of sexual offenses }\end{array}$} \\
\hline & & & & & & & & \\
\hline Low or very low & 24 & $53.3 \%$ & 22 & $88 \%$ & 9 & $90 \%$ & 12 & $100 \%$ \\
\hline High or very high & 21 & 46.66 & 3 & $22 \%$ & 1 & $10 \%$ & 0 & \\
\hline
\end{tabular}

Table 5. List of the population with Maya occurrence of violence, homicide and women, femicide and sexual crimes municipalities in Yucatan Mexico.

\begin{tabular}{|c|c|c|c|c|c|c|c|c|}
\hline \multirow{2}{*}{\begin{tabular}{|c|} 
Risk factor \\
$\begin{array}{c}\text { Percentage of } \\
\text { Maya population }\end{array}$ \\
\end{tabular}} & \multicolumn{2}{|c|}{$\begin{array}{l}\text { Municipalities with cases } \\
\text { of domestic violence }\end{array}$} & \multicolumn{2}{|c|}{$\begin{array}{c}\text { Municipalities with cases } \\
\text { of killing of woman }\end{array}$} & \multicolumn{2}{|c|}{$\begin{array}{l}\text { Municipalities with cases } \\
\text { of femicide typified }\end{array}$} & \multicolumn{2}{|c|}{$\begin{array}{c}\text { Municipalities with cases } \\
\text { of sexual offenses }\end{array}$} \\
\hline & & & & & & & & \\
\hline Low and very low & 17 & $37.7 \%$ & 18 & $72 \%$ & 9 & $90 \%$ & 10 & $83.33 \%$ \\
\hline $\begin{array}{l}\text { Medium to high } \\
\text { Percentage }\end{array}$ & 28 & $62.3 \%$ & 7 & $28 \%$ & 1 & $10 \%$ & 2 & $16.66 \%$ \\
\hline
\end{tabular}




\section{Discussion and Conclusion}

The perspective of risk with geospatial analysis suggests that gender violence is associated with vulnerabilities and also extends as structural phenomenon involving the public dimension, the private and personal. It is also involved in violence against women aspects-social, economic, political, and cultural context.

Also this research showed that, in femicide risk age group, women that suffer domestic violence are $31 \%$ of 20 - 29 and $29 \%$ of 40 to 49 years old; while $40 \%$ of homicide and femicide are 25 to 34 years old, in 15 - 24 years it occurred $33 \%$ and $12 \%$ of 30 - 34 years old. Thus, the risk starts at 15 and is deepened from 25 to 34 , matching data reported by the (INEGI, 2011) regarding exposure to violence in the range of 30 - 39 years (Corral, 2009) in his study of murders of women with the highest percentage between 30 and 35, since their study reports that the former couple also rapes and kills women.

The results show that domestic violence was recorded in 45 municipalities in 25 murders of women, femicide in 10 and in 12 sexual offenses; $55.6 \%$ of the municipalities' acts of violence against women were found. These figures contrast with those reported by the Chamber of Deputies in its report of the killings of women in a comparative 2005-2009, which recorded only 4 municipalities and only 7 homicides than good.

This study identified 10 municipalities that recorded between 3 and 4 indicators of violence, which together $30.5 \%$ of the municipalities with violence recorded $2-4$ indicators, places and geographic areas midrange to high risk femicide. The determined efforts of women's organizations have showed the side of feminicide of the dead women in the state; they are various forms, resources and institutions involved, but it is certainly a matter of state that gender violence is invisible; it found matches Lagarde (2011); Corsi (2002); Ortega-Canto, Munguia-Gil, Oliva-Peña, \& Rodriguez-Sosa (2009).

The association analysis of risk factors shows that violence has multiple character as it relates to their geographical determinants; as well as in the case of femicide, killings of women and sexual offenses are found to be phenomena urban challenges associated with medium levels of urban development; regarding domestic violence significant association between Mayan women speakers was recorded in a range of high average population.

Unless the program against violence to women will be accompanied by measures that provide safety, with real punishment of ill treatment, the results will be poor. The work in the gubernamentals institutions was focused on prevention and monitoring of cases of domestic violence, but the femicide figures do not decline, finding that it is similar to be found by Echeburúa and Coral (2009) in a study of prevalence of domestic violence in Spain.

\section{References}

Alencar-Rodrigues, R., \& Quarry, L. (2012). Psycho, Porto Alegre. PUCRS, 43, 116-126.

Aristegui, R. (2015). News Story.

http://aristeguinoticias.com/2807/mexico/2-asesinatos-por-hora-este-2015-cifras-actualizadas-de-homicidios-en-mexico/

Briceño-León, R. (2008). Homicidal Violence in Latin America. Latin America Today, 50, 103-116.

Bronfenbrenner, U. (1977). Experimental toward an Ecology of Human Development. American Psychologist, 32, 513-531. http://dx.doi.org/10.1037/0003-066X.32.7.513

Bronfenbrenner, U. (1987). The Ecology of Human Development. Barcelona: Polity Press.

Cantera, L. M. (2004). Beyond Gender. New Approaches of “New” Dimensions and Directions of Violence in Couples. Athenea Digital, 6. http://redalyc.uaemex.mx/src/inicio/ArtPdfRed.jsp?iCve=53700636

Carvallo, P. M. (2006). Gender, Postmodernism and International Relations. Female Identity in the Discourse of International Organizations. Confines of International Relations and Political Science, 2, 89-100.

CEPAL (2014). Observatorio de la igualdad de género en América Latina. www.cepal.org/.../37185-observatorio-de-igualdad-de-genero-de-americ

Corral, S. (2009). Study of Dating Violence among University Students/As: Chronicity, Severity and Mutuality of Violent Behaviors. Clinical Legal and Forensic Psychopathology, 9, 29-48.

Corsi, J., Dohmen, M. L., Springs, M. A., \& Bonino-Mendez, L. (2002). Male Partner Violence. An Approach to the Diagnosis and Intervention Models. Buenos Aires: Paidos.

Delgado, S., Rodríguez, F., \& González de Rivera, J. (1993). The Methodology in the Psychiatric Study of Homicides. The Epidemiological Method in Health Mental (pp. 307-318). Barcelona: Masson/Salvat.

Domenech, M., \& Iniguez, L. (2002). The Social Construction of Violence. Digital Athena, 2.

http://blues.uab.es/athenea/num2/domenech.pdf 
Echeburúa, E., \& De Corral, P. (2009). Murder in the Relationship: A Psychological Analysis. Eguzkilore, No. 23, $139-150$.

Ferrández, E. (2006). Violence from a Gender Perspective. Madrid: Psychoanalytic Center of Madrid. http://centropsicoanaliticomadrid.com/antigua/revista/3/art4.html

Gonzalez-Perez, G. J., Vega-Lopez, M., Cabrera-Pivaral, C. E., Vega-Lopez, A., \& Munoz-de la Torre, A. (2012). Mortality from Homicide in Mexico: Trends, Socio-Geographicvariations and Factorsassociated. Science \& Public Health, 17, 3195-3208. http://www.redalyc.org/articulo.oa?id=63024424005

Heise, D. R. (1987). Affect Control Theory: Concepts and Model. Journal of Mathematical Sociology, 13, 1-33. http://dx.doi.org/10.1080/0022250X.1987.9990025

INEGI (2006). National Survey of Household Relations. www.inegi.org.mx

INEGI (2011). National Survey of Household Relations. www.inegi.org.mx

Lagarde, M. (2011). Preface: Feminists around Key Femicide. In R.-L. Fregoso (Ed.), Theoretical, Political and Legal Construction (pp. 11-41). Femicide in Latin America, Mexico: Center for Interdisciplinary Research in Science and Humanities (CEIICH) —UNAM/Researchers Network for Life and Liberty for Women (Feminist Diversity).

Monárrez, J., \& Fuentes, C. (2004). Feminicidio y marginalidad urbana en Ciudad Juárez en la década de los noventa. In F. Martha Torres (Comp.), Violencia contra las mujeres en contextos urbanos y rurales (pp. 43-70). México: El Colegio de México.

Olaiz, G., Rojas, R., Valdez, R., Franco, A., \& Palma, O. (2006). Prevalence of Different Types of Violence Are Health Sector in Mexico. Salud Publica de Mexico, 48, S232-S238.

Oliva-Peña, Y., \& Santana-Carvajal, A. (2004). Different Looks of Gender Violence in Intimate Relationships in a Suburban Population. In M. Port-Solis, \& J. Ortega-Canto (Eds.), Research and Health in the Southeast Region of Mexico (pp. 76-87). Merida: Autonomous University of Yucatán.

Ortega-Canto, J. E., Munguia-Gil, B., Oliva-Peña, Y., \& Rodriguez-Sosa, M. (2009). Monitoring of Social and Gender Violence. Bases for Implementation. Merida: Editorial UADY.

Reed, E., Raj, A., Miller, E., \& Silverman, J. G. (2010). Losing the Gender in Gender Based Violence: The Missteps of Research on Dating and Intimate Partner Violence. Violence against Women, 16, 348-354. http://dx.doi.org/10.1177/1077801209361127

Robles, A. L., \& Cazares, C. S. (2009). Gender Equity. A Distinct Opportunity to Be Children. Hopscotch, 1, 32-53.

Robles, A. L., \& Hurtado de Mendoza, T. (2009). Study on the Perception of the Concept of Gender Equality among the Youth of the Granting Me. Hopscotch, 1, 48-53.

Rodriguez-Angulo, E., Andueza-Pech, G., \& Montero-Cervantes, L. (2012). A Qualitative Study of Maternal Deaths in Tizimin, Yucatan, Mexico. Otherness, 22, 145-158.

Soberón, G., Zurita, B., Ramírez, T., \& Torres, J. (2000). Violence as a Serious Problem Public Health. http://www.bvsde.paho.org/bvsacd/cd51/grave.pdf

Turinetto, A. Q., \& Vicente, P. C. (2008). Male Abusers: Psychological Treatment of Abusers. Madrid: Group 5 Action and Social Management.

UNODC (2013). Global Study on Homicide. Viena. https://www.unodc.org/.../2014_global_homicide_book_web.pdf

Walker, L. E. (2004). The Profile of Women Victims of Violence. In J. Sanmartín (Ed.), The Labyrinth of Violence: Causes, Types and Effects (pp. 205-218). Barcelona: Editorial Ariel.

Women Network (2010). Report Femicide in the State of Yucatan. www.ovsgyucatan.uady.mx/.../relacion_de_feminicidios_en_yucatan.do

World Health Organization (2003). World Report on Violence and Health. http://archivos.diputados.gob.mx/Centros Estudio/ceameg/violencia/siv1/doctos/imsvcompleto.pdf

Yanes, M. (2006). Relationship between the Index of Marginalization and Homicide Rates for the Municipalities of the States with the Highest Levels of Violence in 2000 and 2005. Thesis Presented for the Degree by Master in Demography, Tijuana: El Colegiode la Frontera Norte.

Ybáñez, Z., \& Yanes, M. (2013). Homicide and Marginalization in Urban Municipalities of the Most Violent States in Mexico, 2000-2005. Demographic and Urban Studies, 28, 291-322. http://www.redalyc.org/articulo.oa?id=31230010001 